\title{
IMPLEMENTASI JARINGAN SENSOR NIRKABEL ZIGBEE MENGGUNAKAN TOPOLOGI MESH PADA PEMANTAUAN DAN KENDALI PERANGKAT RUANG
}

\author{
Fathur Zaini Rachman ${ }^{1}$, Armin $^{2}$, Nur Yanti ${ }^{3}$, Qory Hidayati ${ }^{4}$ \\ 1,2,3,4 Jurusan Teknik Elektronika, Politeknik Negeri Balikpapan \\ Email: ${ }^{1}$ fozer85@ gmail.com, ${ }^{2}$ armin @ poltekba.ac.id, ${ }^{3}$ nur.yanti@ poltekba.ac.id, ${ }^{4}$ qory.hidayati@ poltekba.ac.id
}

(Naskah masuk: 25 Agustus 2017, diterima untuk diterbitkan: 28 September 2017)

\begin{abstract}
Abstrak
Sistem pemantau dan kendali memiliki fungsi untuk merekap data dan mengakses perangkat ruangan yang terpasang pada setiap titik pemasangan. Komunikasi yang digunakan adalah komunikasi nirkabel ZigBee dengan menggunakan topologi mesh. Coordinator merupakan pusat data yang terhubung langsung ke komputer, dan hasilnya ditampilkan dalam bentuk HMI, sehingga seorang operator dapat dengan mudah memantau dan mengendalikan perangkat-perangkat yang terpasang pada ruangan. Perangkat ruangan terdiri dari sensor diantaranya PIR, arus, pendeteksi asap dan sidik jari, yang kesemuannya terhubung dengan arduino yang bertugas sebagai pemroses data untuk membentuk protokol-protokol yang akan dikirim dari titik end device ke coordinator. Hasil pengujian jarak pengiriman antara titik pemasangan ZigBee maksimal 93 meter tanpa halangan dan 30 meter dengan halangan. Adapun throughput pengiriman data dari end device dan simulator ke titik coordinator akan semakin besar jika delay diperkecil dan paket data diperbesar dalam setiap pengirimannya. Hasil dari packet loss pada pengujian didapatkan $4,94 \%$, ini dikarenakan faktor floating yang terjadi pada arduino.
\end{abstract}

Kata kunci: ZigBee, topologi mesh, throughput, packet loss

\begin{abstract}
The monitoring and control system has the function of recording data and accessing the installed room equipment. The communication used is ZigBee wireless communication with mesh topology. The coordinator is a data center connected directly to the computer, and the results are displayed in the form of HMI, so that an operator can easily monitor and control the devices installed in the room. The room equipment consists of sensors such as PIR, current, smoke detector and fingerprint, all of which are connected to the arduino that serves as data processors in the form of protocols to be sent from the end device point to the coordinator. The result of test, delivery distance between ZigBee installation point is 93 meters away without obstruction and 30 meter with obstacle. The data transmission throughput from the end device and simulator to the coordinator point will be greater if the delay is reduced and the data packet enlarged in each delivery. The result of packet loss in the test is $4.94 \%$, this is due to floating factor.
\end{abstract}

Keywords: ZigBee, topologi mesh, throughput, packet loss

\section{PENDAHULUAN}

Saat ini, hampir semua perangkat ruangan di perkantoran, hotel, kampus dan instansi-instansi pemerintah atau swasta sudah dilengkapi dengan sistem keamanan ruangan, mulai penggunaan kunci, password keypad hingga teknologi RFID pada setiap pintu untuk meningkatkan keamanaan ruangan. Dimulai dari sistem keamanan ruang menggunakan pin pada keypad dan kecerdasan ruang menggunakan multi sensor (Kamolan, 2016). Dari beberapa teknologi tersebut, yang paling banyak diimplementasikan adalah teknologi RFID yang difungsikan untuk akses pintu yang memiliki beberapa ruangan yang bertingkat dan banyak pada setiap bangunan. Seiring dalam penggunaan ternyata ditemukan beberapa kendala oleh pengguna, seperti hilang, lupa dan bahkan penyalahgunaan kartu RFID. kemudian dilanjutkan lagi dengan teknologi fingerprint yang ditambah dengan kemajuan sensor dan mikrokontroler sehingga membuat suatu ruangan menjadi lebih cerdas, ruangan dilengkapi dengan sensor tambahan seperti sensor sidik jari sebagai akses pintu ruangan dan sensor PIR (Passive Infrared Receiver) sebagai sensor gerak yang difungsikan untuk kendali lampu ruangan (Saputra, 2014) dan sistem pengaturan pencahayaan ruangan dalam penghematan energi (Putro, 2016). Teknologi yang diterapkan untuk akses ruang terus berkembang hingga penggunaan yang berlapis yaitu RFID, PIN pada keypad, sidik jari yang juga dilengkapi dengan penyimpanan data dan notifikasi diharapkan dapat meningkatkan keamanan ruang (Suhendro, 2016). Kemudian teknologi nirkabel dalam kecerdasan ruang menjadi solusi dalam intalasi kabel yang banyak khususnya pada multi sensor pada akses ruang smart home (Rachman, 2016) dan bidang medis salah satunya pada 
monitoring tetes infus menggunakan jaringan nirkabel dengan topologi star (Rachman, 2015). Teknologi itu semua hanya sebatas pada akses ruang dan kecerdasannya yang berdiri sendiri pada setiap ruang. Sedangkan pada kenyataannya perkembangan dibutuhkan akses ruang yang banyak seperti pada laboratorium kampus ataupun tempat lain yang memerlukan pemantauan dan kendali pada setiap ruang, agar dapat terjamin keamanannya.

Pada penelitian ini membahas bagaimana membangun suatu sistem pemantau dan kendali ruang yang berpusat dengan menggunakan jaringan nirkabel ZigBee pada gelombang 2,4 GHz, terdiri dari beberapa perangkat diantaranya end device sebagai titik pemasangan, router sebagai jembatan penghubung antara end device dengan coordinator serta pengujian kinerja dari ZigBee itu sendiri. Selain itu, sistem pemantauan dan kendali ditampilkan dalam bentuk HMI (Human Machine Interface) sehingga mudah digunakan oleh operator dalam pengoperasiannya.

\section{Komunikasi ZigBee}

ZigBee adalah suatu modul RF yang memilki kecepatan data rendah (low data rate), biaya murah (low cost) yang berkerja pada jaringan nirkabel jarak pendek. ZigBee beroperasi pada frekuensi $868 \mathrm{MHz}$, $915 \mathrm{MHz}$ serta 2,4 GHz. Data rate maksimum adalah $250 \mathrm{Kbps}$ (Farahani, 2008) (Firdaus, 2014). Salah satu bentuk fisik teknologi ini seperti pada gambar 1 di bawah ini .

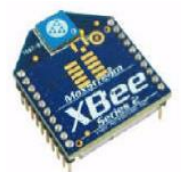

Gambar 1. Zigbee

ZigBee memiliki berbagai jenis jangkauannya dan topologi jaringan seperti star dan mesh.

A. Jaringan Mesh

Seperti pada gambar 2, jaringan mesh adalah jaringan komunikasi yang terdiri dari client mesh (node), mesh dan router gateway dan terhubung menggunakan topologi mesh. Node bisa berupa laptop, ponsel dan perangkat nirkabel lainnya (Firdaus, 2014).

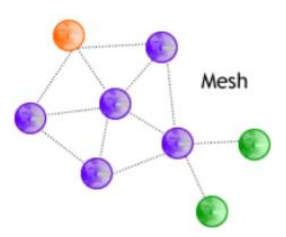

Gambar 2. Topologi Mesh

Dalam penerapannya jaringan mesh memiliki kelebihan dalam jarak, karena setiap node saling terhubung sehingga sangat memungkinkan pengiriman. Sedangkan jaringan yang menggunkan topologi star jarak jangkauan lebih pendek, karena setiap node pemasangan hanya dapat mengirim dan menerima data sesuai dengan jarak yang dimiliki oleh ZigBee, sehingga topologi ini tidak cocok jika diterapkan di ruang lingkup yang luas.

\section{B. Kinerja Coordinator ZigBee}

Dalam pengujian kinerja coordinator dibagi menjadi 2 bagian, yaitu pengujian throughput dan packet loss.

Throughput menunjukkan banyaknya data yang dapat diterima oleh coordinator dalam selang waktu tertentu, throughput pada besarnya trafik yang terdapat pada jaringan. Throughput dapat dihitung dengan persamaan sebagai berikut (B. Preveze, 2010):

$$
\operatorname{Tg}\left(\frac{\text { byte }}{\mathrm{s}}\right)=\frac{D b * r x}{T(s)}
$$

Keterangan:

$\mathrm{Db}=$ Data Byte

$\mathrm{Tg}=$ Throughput

rx = data yang diterima

$\mathrm{T}=$ waktu (detik)

Packet loss adalah data-data yang terkirim dari titik pemasangan hingga ke titik coordinaor yang mana data-data tersebut tidak diterima oleh coordinator (Shamsi, 2010). Perhitungan packet loss dalam suatu pengirman dapat diketahui dengan menggunakan persamaan (Koul).

$$
P L_{T}=\left(1-\frac{n T r e c v}{n T s e n t}\right) \times 100 \%
$$

Pad pengujian throughput, semua perangkat pada satu lingkup jaringan mengirim data ke titik coordinator maka terjadi perubahan jumlah data yang dikirim maupun yang diterima. Dari perubahan tersebut didapatkan packet loss, adapun perhitungan untuk mendapatkan rata-rata dari packet loss tersebut dapat menggunakan persamaan.

$$
\text { Rata }- \text { rata } P L_{T}=\frac{1}{n} \sum_{i=1}^{n} x i
$$

Dengan pengujian pengiriman data yang diterima maka akan didapat packet loss, dalam pengujiannya dilakukan dengan peningkatan jumlah data yang dikirim dari titik perangkat atau end device ke titik coordinator.

\section{Model Sistem}

Pada model sistem, dibagi menjadi 3 bagian yaitu end device, router dam coordinator. Adapun perancangannya seperti pada gambar 3 .

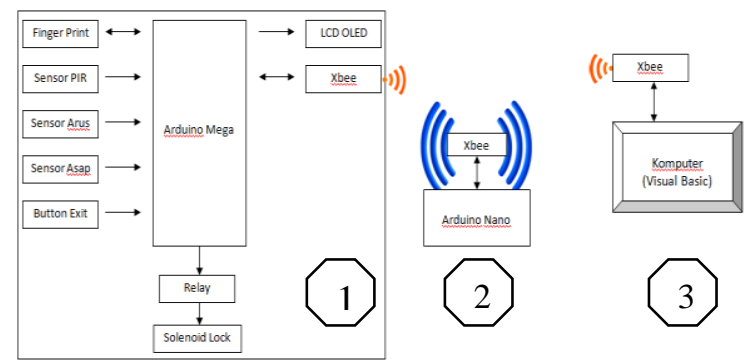

Gambar 3. Model Sistem Komunikasi 
Keterangan :
1: End device (titik perangkat)
2: Router
3: Coordinator (pusat data)

Model sistem komunikasi terdiri dari end device, router dan coorfinator, end device sebagai pusat informasi dan pengolahan data-data sensor dan perangkat-perangkatnya ruangan, data dibentuk menjadi sebuah protokol-protokol. Router berfungsi sebagai penghubung pertukaran protokol data yang dikirim dari atau ke titik coordinator. Sedangkan coordinator sebagai pusat kendali dan pemantauan keadaan ruangan dalam satu jaringan yang sama.

A. Konfigurasi ZigBee (xbee)

Konfigurasi xbee menggunakan software XCTU dan konfigurasi tersebut akan tetap ada meskipun xbee dimatikan sementara, konfigurasi xbee end device router dan coordinator dapat dilakukan sekaligus asalkan ketiga xbee terhubung ke komputer. Konfigurasinya seperti pada tabel 1.

Tabel 1. Konfigurasi xbee

\begin{tabular}{|c|c|c|}
\hline Xbee & Configuration & value \\
\hline \multirow{8}{*}{$\begin{array}{l}\text { Port :COM5- } \\
\text { 9600/8/N/1/ } \\
\text { N-AT } \\
\text { Mac : } \\
\text { 0013A20040 } \\
\text { A0AF69 }\end{array}$} & CH Channel & $\mathrm{C}$ \\
\hline & ID pan ID & 3332 \\
\hline & $\begin{array}{l}\text { DH (Destination Address } \\
\text { High) }\end{array}$ & 0 \\
\hline & $\begin{array}{l}\text { DL (Destination Address } \\
\text { Low) }\end{array}$ & 0 \\
\hline & $\begin{array}{l}\text { SH (Serial Number } \\
\text { High) }\end{array}$ & 13A200 \\
\hline & SL (Serial Number Low) & 40A0AF69 \\
\hline & CE Coordinate Enable & $\begin{array}{l}\text { Coordinate } \\
{[1]}\end{array}$ \\
\hline & NI Node Identifier & Coordinator \\
\hline \multirow{8}{*}{$\begin{array}{l}\text { Port } \\
: \text { COM15- } \\
9600 / 8 / \mathrm{N} / 1 / \\
\text { N-AT } \\
\text { Mac } \\
: 0013 \mathrm{~A} 2004 \\
\text { 0936D2D }\end{array}$} & CH Channel & $\mathrm{C}$ \\
\hline & ID pan ID & 3332 \\
\hline & $\begin{array}{l}\text { DH (Destination Address } \\
\text { High) }\end{array}$ & $13 \mathrm{~A} 200$ \\
\hline & $\begin{array}{l}\text { DL (Destination Address } \\
\text { Low) }\end{array}$ & 40A0AF69 \\
\hline & $\begin{array}{l}\text { SH (Serial Number } \\
\text { High) }\end{array}$ & $13 \mathrm{~A} 200$ \\
\hline & SL (Serial Number Low) & 40936D2D \\
\hline & CE Coordinate Enable & $\begin{array}{l}\text { End device } \\
{[0]}\end{array}$ \\
\hline & NI Node Identifier & Ruang1 \\
\hline \multirow{8}{*}{$\begin{array}{l}\text { Port :COM4- } \\
\text { 9600/8/N/1/ } \\
\text { N-AT } \\
\text { Mac : } \\
\text { 0013A20040 } \\
\text { A0AF9A }\end{array}$} & CH Channel & $\mathrm{C}$ \\
\hline & ID pan ID & 3332 \\
\hline & $\begin{array}{l}\text { DH (Destination Address } \\
\text { High) }\end{array}$ & $13 \mathrm{~A} 200$ \\
\hline & $\begin{array}{l}\text { DL (Destination Address } \\
\text { Low) }\end{array}$ & 40A0AF69 \\
\hline & $\begin{array}{l}\text { SH (Serial Number } \\
\text { High) }\end{array}$ & $13 \mathrm{~A} 200$ \\
\hline & SL (Serial Number Low) & 40A0AF9A \\
\hline & CE Coordinate Enable & $\begin{array}{l}\text { End device } \\
{[0]}\end{array}$ \\
\hline & NI Node Identifier & Ruang2 \\
\hline
\end{tabular}

Konfigurasi xbee dimaksudkan agar komunikasi data antar xbee dapat dikirim sesuai penerima dan dapat ditampilkan hasil pengirimannya.
B. Proses kerja Jaringan xbee

Pada setiap titik jaringan memiliki proses kerja masing-masing sesuai dengan fungsi dan perannya dalam jaringan. Pada gambar 4, merupakan alir proses data pada end device.

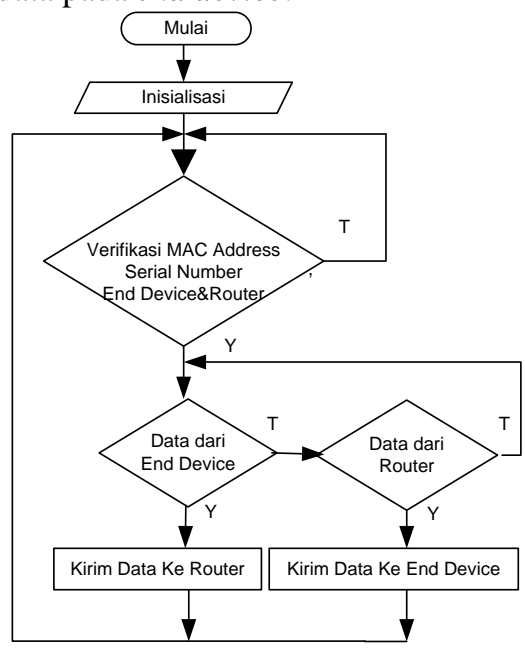

Gambar 4. Diagram Alir End device

Dalam proses pengiriman data xbee memiliki pengaturan berbeda antara router dan end device, selanjutnya xbee end device dan xbee router akan melakukan verifikasi, yaitu konfigurasi end device dan router itu sendiri, serial number high dan serial number low dari router sebagai protokol dan jika data berasal dari end device maka data dikirim ke router namun jika data asalnya dari router maka end device akan menerima data.

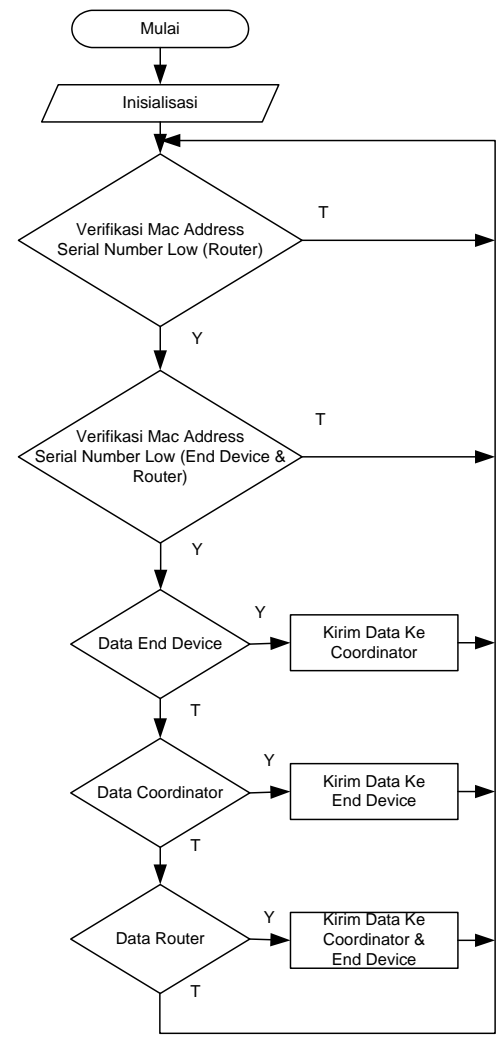

Gambar 5. Diagram Alir Router 
Pada gambar 5, merupakan alir proses data pada router yang merupakan jembatan penghubung pertukaran data antara end device dengan coordinator. Dalam proses pengiriman data xbee router akan melakukan verifikasi, yaitu konfigurasi router itu sendiri, serial number high dan serial number low dari Coordinator dan end device sebagai protokol dan jika data berasal dari end device maka data dikirim ke Coordinator, jika data asalnya dari Coordinator maka data akan dikirim ke end device, dan jika data berasal dari router maka data dikirim ke end device dan Coordinator.

Pada gambar 6, merupakan titik penerimaan data yang masuk ataupun yang keluar menuju router.

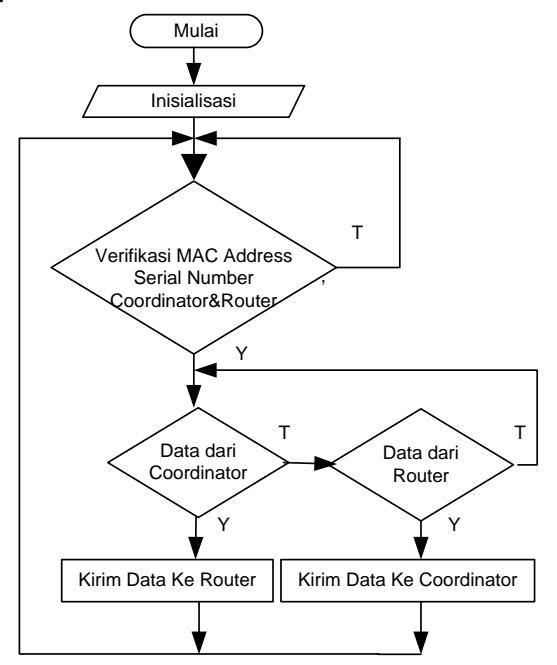

Gambar 6. Diagram Alir Coordinator

Dalam proses pengiriman data xbee Coordinator akan melakukan verifikasi, yaitu konfigurasi Coordinator itu sendiri, serial number high dan serial number low dari router sebagai protokol dan jika data berasal dari Coordinator maka data dikirim ke Router namun jika data asalnya dari router maka Coordinator akan menerima data.

C. Protokol Data

Untuk mempermudah dan mengamankan data pada jaringan yang dilalui maka diperlukan protokol data seperti pada gambar 7 .

\section{\begin{tabular}{|l|l|l|l|l|l|l|}
\hline * & $\mathrm{R}$ & $\mathrm{P}$ & $\mathrm{S}$ & $\mathrm{I}$ & $\mathrm{N}$ & \# \\
\hline
\end{tabular}}

Gambar 7. Protokol Data

Keterangan:

$$
\begin{array}{ll}
* & : \text { Start Data } \\
\mathrm{R} & : \text { Ruangan } \\
\mathrm{P} & : \text { Sensor Gerak } \\
\mathrm{S} & : \text { Sensor Asap } \\
\mathrm{I} & \text { : Sensor Arus } \\
\mathrm{N} & \text { : Identitas Pemakai } \\
\# & \text { : End Data }
\end{array}
$$

Prorokol data terdiri dari 7 byte, setiap byte memiliki fungsi masing-masing dalam komunikasi data. Simbol $\left(^{*}\right)$ berfungsi sebagai byte awal dari prokol data, simbol (R) berfungsi sebagai byte identitas ruangan, simbol $(P)$ berfungsi sebagai byte pendeteksi keberadaan pengguna ruangan, simbol (S) berfungsi sebagai byte pendeteksi asap pada rungan, simbol (I) berfungsi sebagai byte penggunaan daya yang terpakai pada suatu rungan, simbol ( $N$ ) berfungsi sebagai Identitas pengguna ruangan yang terekap pada basis data pada modul fingerprint, dan yang terakhir simbol (\#) berfungsi sebagai byte akhir dari protokol pengiriman data.

\section{Pengujian dan Hasil}

Pengujian dilakukan untuk memastikan kinerja alat yang digunakan seperti jarak, throughput, packet error dan hasil paket data yang diterima pada panel.

A. Jangkauan ZigBee

Pengujian dilakukan seperi pada gambar 8 , yang terdiri pengirim (htx) dan penerima (hrx).

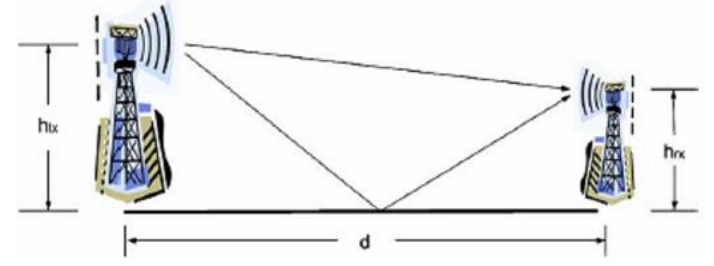

Gambar 8. Variasi Jarak dan Tinggi Pengiriman

Pengiriman dilakukan dengan jarak, tinggi pengiriman dan penerimaan berbeda-beda. Serta dilakukan pengiriman dengan ada dan tanpa halangan.

\section{> Pengujian Dengan Ada Halangan}

Pengujian dilakukan dengan halangan, dan halangan di sini adalah berupa tembok dan pintu ruangan.

- Tinggi Pengiriman (htx) $0 \mathrm{~cm}$

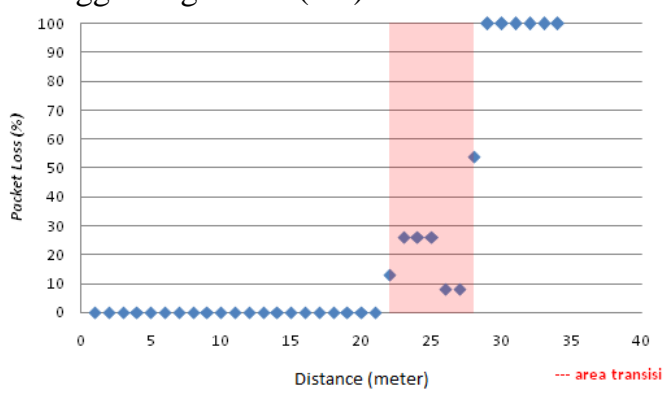

Gambar 9. Tinggi Pengiriman $0 \mathrm{~cm}$ dari Penerima

- $\quad$ Tinggi Pengiriman (htx) $40 \mathrm{~cm}$

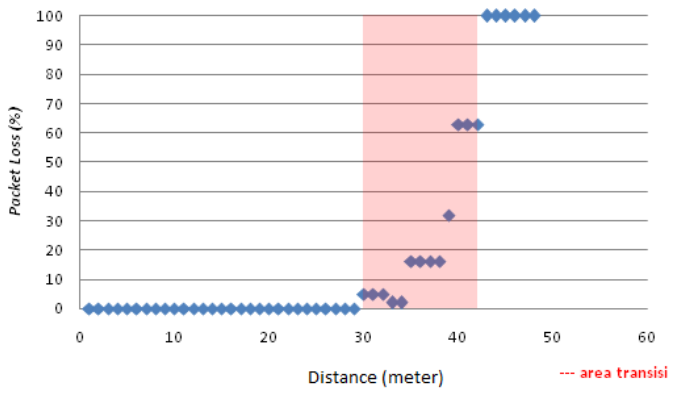

Gambar 10. Tinggi Pengiriman $40 \mathrm{~cm}$ dari Penerima 
- Tinggi Pengiriman (htx) $80 \mathrm{~cm}$

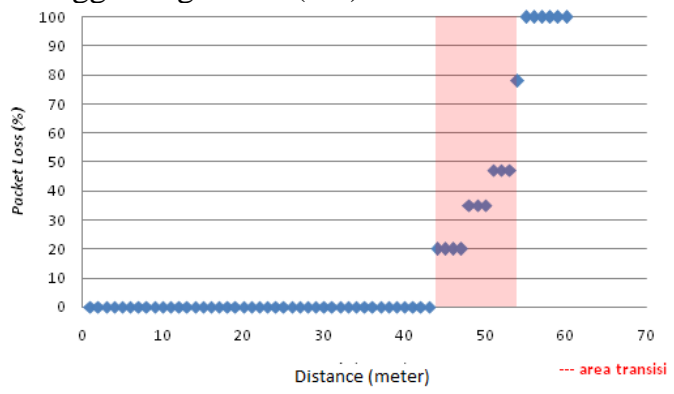

Gambar 11. Tinggi Pengiriman $80 \mathrm{~cm}$ dari Penerima

- Tinggi Pengiriman (htx) $120 \mathrm{~cm}$

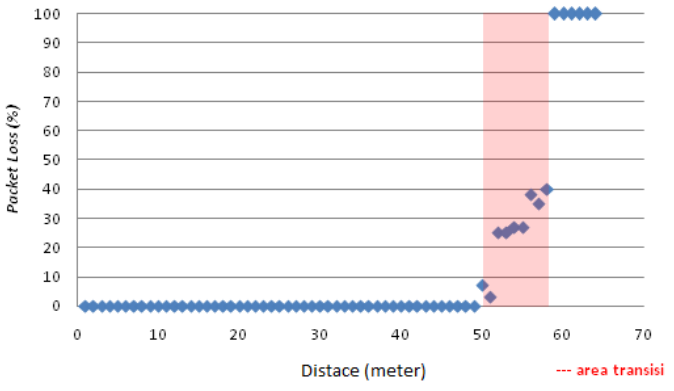

Gambar 12. Tinggi Pengiriman $120 \mathrm{~cm}$ dari Penerima

- $\quad$ Tinggi Pengiriman (htx) $160 \mathrm{~cm}$

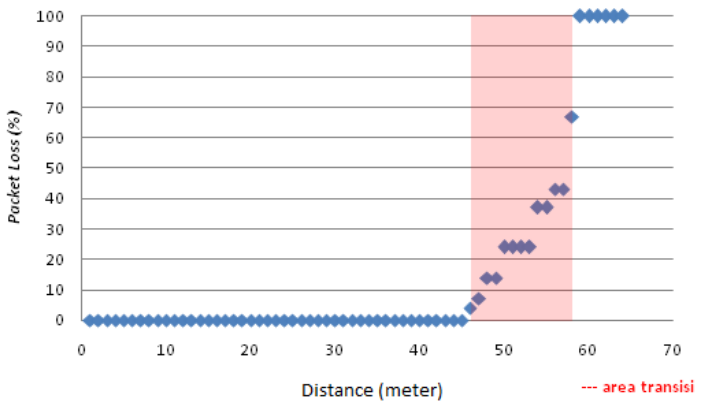

Gambar 13. Tinggi Pengiriman $160 \mathrm{~cm}$ dari Penerima

Seperti pada gambar 9 sampai 13 Jarak pengirman terbaik terdapat pada ketinggian pengiriman $120 \mathrm{~cm}$ dengan jarak 49 meter dengan ada halangan.

\section{$>$ Pengujian Tanpa Ada Halangan}

Pengujian dilakukan dengan tanpa ada halangan dengan ketinggian $120 \mathrm{~cm}$ dari ketinggian penerima. Adapun hasil dari pengujiannya seperti pada tabel 1 .

Tabel 1. Pengujian Pengiriman Tanpa Halangan

\begin{tabular}{|c|c|c|}
\hline No & $\begin{array}{c}\text { Jarak } \\
\text { (Meter) }\end{array}$ & $\begin{array}{c}\text { Data } \\
\text { Terkirim }\end{array}$ \\
\hline 1 & 1 & Ya \\
\hline 2 & 10 & Ya \\
\hline 3 & 20 & Ya \\
\hline 4 & 30 & Ya \\
\hline 5 & 40 & Ya \\
\hline 6 & 50 & Ya \\
\hline 7 & 60 & Ya \\
\hline 8 & 70 & Ya \\
\hline
\end{tabular}

\begin{tabular}{|c|c|c|}
\hline 9 & 80 & Ya \\
\hline 10 & 90 & Ya \\
\hline 11 & 91 & Ya \\
\hline 12 & 93 & Ya \\
\hline 13 & 94 & Ya/Tidak \\
\hline 14 & 100 & Ya/Tidak \\
\hline 15 & $>100$ & Tidak \\
\hline
\end{tabular}

Pengiriman maksimal dengan tanpa ada halangan maksimal 93 meter dan jarak 94 meter hingga 100 meter merupakan jarak transisi pengiriman, yaitu ada dan tidak data yang diterima pada penerima. Pada jarak lebih dari 100 meter, semua data tidak ada yang diterima pada titik coordinator.

B. Throughput $(T g)$

Dari jumlah paket data yang masuk dan lamanya pengambilan data, akan dapat diketahui throughput pada suatu jaringan. Pada pengujian ini, menggunakan simulator pengiriman paket data yang bervariasi dari 7, 14, 21, 28, 35, 42, 49, 56, 63, 70, 77 hingga 84 byte dengan delay 1 detik.

Tabel 2. Throughput Pengiriman

\begin{tabular}{|c|c|c|c|c|}
\hline No & $\begin{array}{c}\mathrm{D} 1 \\
(\text { byte })\end{array}$ & $\begin{array}{c}\mathrm{D} 2 \\
(\text { byte })\end{array}$ & $\begin{array}{c}\mathrm{C} \\
\text { (byte) }\end{array}$ & $\begin{array}{c}\text { Tg } \\
(\text { byte })\end{array}$ \\
\hline 1 & 7 & 7 & 840 & 14 \\
\hline 2 & 7 & 14 & 1204 & 20 \\
\hline 3 & 7 & 21 & 1620 & 27 \\
\hline 4 & 7 & 28 & 1975 & 32 \\
\hline 5 & 7 & 35 & 2360 & 39 \\
\hline 6 & 7 & 42 & 2776 & 46 \\
\hline 7 & 7 & 49 & 3154 & 52 \\
\hline 8 & 7 & 56 & 3555 & 59 \\
\hline 9 & 7 & 63 & 3896 & 64 \\
\hline 10 & 7 & 70 & 4376 & 72 \\
\hline 11 & 7 & 77 & 4895 & 81 \\
\hline 12 & 7 & 84 & 5130 & 85 \\
\hline
\end{tabular}

Pada Tabel 2, hasil pengujian throughput transmisi dilakukan dengan 12 kali pengujian, pada pengujian terdiri dari perangkat (D1) yang merupaka sumber paket data yang melakukan pengiriman 7 byte setiap detiknya. Simulator (D2) pada pengujian ini melakukan pengiriman paket data yang bervariasi untuk menguji trafik yang ada pada jaringan, setiap pengiriman yang dilakukan oleh simulator merupakan implementasi dari banyaknya perangkat yang digunakan.

C. Packet Loss

Packet loss merupakan paket data yang hilang dari semua pengiriman ke titik coordinator (rachman, 2016). Pada pengujian ini, dapat dilihat pada tabel 3 , data dikirim setiap 1 detik selama 1 menit.

Tabel 3. Packet Loss

\begin{tabular}{|c|c|c|}
\hline \multicolumn{2}{|c|}{ Byte / menit } & \multirow{2}{*}{$\boldsymbol{P L}_{\boldsymbol{T}}(\boldsymbol{\%})$} \\
\hline nT recv & $\boldsymbol{n T \text { sent }}$ & \\
\hline 840 & 840 & 0 \\
\hline 1204 & 1260 & 4,44 \\
\hline 1620 & 1680 & 3,57 \\
\hline 1975 & 2100 & 5,95 \\
\hline 2360 & 2520 & 6,34 \\
\hline
\end{tabular}




\begin{tabular}{|l|l|l|}
\hline 2776 & 2940 & 5,57 \\
\hline 3154 & 3360 & 6,13 \\
\hline 3555 & 3780 & 5,95 \\
\hline 3896 & 4200 & 7,23 \\
\hline 4376 & 4620 & 5,28 \\
\hline 4895 & 5040 & 2,87 \\
\hline 5130 & 5460 & 6,04 \\
\hline
\end{tabular}

Dengan menggunakan persamaan 3, maka dapat diketahui rata-rata packet loss pada pengujian ini yaitu $4,94 \%$.

D. Paket Data

Pada Tabel 4, Paket data yang dikirim dari titik end device ke coordinator dan hasinya ditampilkan pada HMI menggunkan Visual Basic melalui jalur komunikasi serial.

Tabel 4. Hasil Tampilan Pada HMI

\begin{tabular}{|c|c|c|c|c|c|c|}
\hline & Protokol & \multicolumn{5}{|c|}{ Tamplan pada HMI } \\
\cline { 4 - 7 } Senis & $\begin{array}{c}\text { Data } \\
\text { (byte })\end{array}$ & Room & PIR & Asap & Arus & ID \\
\hline $\begin{array}{c}\text { Finger } \\
\text { Print }\end{array}$ & $* 10000 \#$ & 1 & 0 & 0 & 0 & 0 \\
\hline PIR & $* 11000 \#$ & 1 & Ada & 0 & 0 & 0 \\
\hline Asap & $* 11100 \#$ & 1 & Ada & Ada & 0 & 0 \\
\hline Arus & $* 11110 \#$ & 1 & Ada & Ada & 1 A & 0 \\
\hline $\begin{array}{c}\text { Finger } \\
\text { Print }\end{array}$ & $* 11111 \#$ & 1 & Ada & Ada & Ada & 1 \\
\hline
\end{tabular}

Paket data dikirim sebanyak 7 byte, byte pertama $\left(^{*}\right)$ sebagai start byte, byte kedua sebagai identitas ruangan, byte ketiga sebagai pendeteksi keberadaan orang, byte ke empat sebagai pendeteksi asap, byet ke lima sebagai informasi penggunaan arus pada suatu ruangan, byte ke enam sebagai identitas pemakai ruangan dan byte ke tujuh (\#) sebagai akhir data byte yang dikirim.

\section{KESIMPULAN}

Maksimal jarak pengiriman data (tanpa ada halangan) dari titik end device ke coordinator adalah 93 meter dengan jumlah data yang dikirim 7 byte dengan ketinggian pengiriman 1,6 meter. Pada jarak 94 meter hingga 100 meter merupakan jarak transisi, paket data sering terjadi kegagalan dalam pengiriman (packet loss). Pada Jarak 100 meter lebih sudah tidak ada lagi data yang diterima oleh titik coordinator. jumlah throughput sebanding lurus dengan banyak data yang yang diterima oleh coordinator. Packet loss diambil dari pengujian throughput dan dilakukan pada jarak yang masih dapat dijangkau oleh jaringan. Rata-rata packet loss pada pengujian ini adalah $4,94 \%$.

\section{DAFTAR PUSTAKA}

KAMOLAN, A. \& SAMPEBATU, L., 2016, Rancang Bangun Prototipe Pengaman Ruangan Dengan Input Kode Pin dan Multi Sensor Berbasis Mikrokontroler, Prosiding SNTI IV.

SAPUTRA, D., 2014, Akses Kontrol RuangMenggunakan Sensor Sidik Jari Berbasis Mikrokontroler ATMEGA328P, Prosiding SENTIKA.

PUTRO, KAMBEY, 2016, Sistem Pengaturan Pencahayaan Ruangan Berbasis Android Pada Rumah Pintar, JNTE Vol: 5, No. 3, November.

SUHENDRO, 2016, Rancang Bangun Prototipe Sistem Kunci Pengaman Pintu Ruang Radiasi Dengan Arduino dan Sistem Operasi Android, Prosiding SNATIF Ke-3.

RACHMAN, 2016, Implementasi Komunikasi Nirkabel Pada Smart Home Berbasis Arduino, Prosiding SNATIF Ke-3.

JAZI EKO, 2014, Pengantar Elektronika \& Instrumentasi, C.V ANDI OFFSET.

FARAHANI, 2008, ZigBee Wireless Networks and Transceivers, Newnes.

RACHMAN, F.Z., 2015, Prototype development of monitoring system in patient infusion with wireless sensor network, IEEE, Page(s) 329402, DOI: 10.1109/ISITIA.2015.220013.

FIRDAUS, 2014, Wireless Sensor Network; Teori dan Aplikasi, Graha Ilmu.

PREVEZE, B., SAFAK, A., 2010, Throughput Improvement of mobile multi-hop wireless network, Internasional Journal of Wireless \& Mobile Networks (IJWMN), vol.2, no.3, August.

SHAMSI,M. \& RAHBAR, A. G., 2010, Packet loss Analysis of Multi-Fiber Asymmetric Shareper-link optical packet switches, Internasional Journal of Advances in Optical Communication and Network, Vol. 1, No.1, Des 2010.

KOUL, M.S, Analysis of The Effects of Packet loss and Delay Jitter on MPEG-4 Video Quality, Dept. of Electric Engineering, Arlington, Texas. 